\title{
Clinical variability of respiratory pulmonary hypertension: implications for diagnosis and management
}

\author{
Lucio Casali ${ }^{*}$, Pierluigi Carratù ${ }^{2}$ and Matteo Sofia ${ }^{3^{\wedge}}$
}

\begin{abstract}
Pulmonary Hypertension (PH) associated to chronic respiratory diseases is currently classified in the $3^{\text {rd }}$ group, as a mild to moderate form of pre-capillary PH that progressively complicates the prognosis of associated pulmonary disease. In clinical practice, however, some unresolved issues in the respiratory PH should be considered: 1) the PH heterogeneity in some respiratory diseases, such as Chronic Obstructive Pulmonary Disease (COPD), where the prevalence of unrecognized left heart disease, or chronic pulmonary thromboembolism may change the clinical classification; 2) the combining form of severe $\mathrm{PH}$ which often is not correlated to chronic ventilator impairment, while outcome is strictly related to pulmonary haemodynamics. The recognition of out of proportion respiratory $\mathrm{PH}$ in several chronic respiratory diseases which include COPD, Idiopathic Pulmonary Fibrosis (IPF), Combined Pulmonary Fibrosis and Emphysema, Obstructive Sleep Apnea (OSA), Obesity Hypoventilation Syndrome (OHS) may be important for a comprehensive clinical classification of severe respiratory $\mathrm{PH}$, as well as, for the inclusion of these patients in randomized clinical trials on $\mathrm{PH}$ targeted therapy.
\end{abstract}

Keywords: Chronic obstructive pulmonary disease, Idiopathic pulmonary fibrosis, Obesity hypoventilation syndrome, Obstructive sleep apnea, Phenotype, Pulmonary hypertension, Pulmonary arterial hypertension

\section{In memoriam}

To the memory of my beloved Master Matteo Sofia, Mentor and Life's Guide, who left me suddenly alone. Yours forever, Pierluigi Carratù.

To the everlasting memory of Prof. Matteo Sofia, great friend and colleague. Lucio Casali.

\section{Review}

Clinical disease classification is an important tool for physicians, in order to distinguish severity and to differently manage a same disorder that can be found in multiple clinical conditions; this is particularly true for pulmonary hypertension [1,2]. Pulmonary Hypertension $(\mathrm{PH})$ is a relatively frequent pathophysiological and haemodynamic state that can be detected in almost 37 clinical syndrome comprising multiple clinical conditions, including chronic left heart disease and lung diseases. The immediate advantages of the updated $\mathrm{PH}$

\footnotetext{
*Correspondence: lucio.casali@unipg.it

Deceased

${ }^{1}$ Respiratory Diseases, University of Perugia, Perugia, Italy

Full list of author information is available at the end of the article
}

clinical classification are the separation of pulmonary arterial hypertension (Gr 1) (a rare disease, with a currently available efficacious treatment in term of lifesavings) from other forms of $\mathrm{PH}$ associated to various disorders (Gr 2 and Gr 3), where specific pharmacological treatments for $\mathrm{PH}$ are discouraged, while the best management is represented by the treatment of associated disease. Actually Pulmonary Arterial Hypertension $(\mathrm{PAH})$ includes different forms that share a similar clinical picture and virtually identical pathological changes of the distal pulmonary arteries which may represent the right substrate for specific therapy. Furthermore, the clinical classification allows the recognition of chronic thromboembolic $\mathrm{PH}$, the only form surgically treatable (Gr 4), and a miscellaneous group of $\mathrm{PH}$ with unclear and/or multifactorial mechanisms (Gr 5) that may induce specialists to seek for important associations, such as ematologic, metabolic, or systemic diseases. Recently, the current 6 groups classification has given the opportunity to adhere to an easy stepwise diagnostic algorithm. There are, however, some limitations for clinical 
classification, especially when there is an inherent non homogeneous epidemiologic distribution with a high prevalence (85\% of all $\mathrm{PH}$ cases) of Gr 2 and Gr $3 \mathrm{PH}$, compared to the other groups. It is likely that improving the concentration of $\mathrm{PH}$ in a same group may increase the clinical variability with differences in $\mathrm{PH}$ phenotype, making clinical evaluation more difficult for the greater interference of confounding factors related to comorbidities, such as age, increasing number of mixed forms, or a grey zone related to the selection of pulmonary haemodinamics criteria. Remarkably, this phenomenon has been reported also for PAH in the recent experience of US and UK registries. Compared to other analyzed comorbidities in PAH patients, hypertension, obesity, diabetes, and Chronic Obstructive Pulmonary Disease (COPD) were associated with significantly worse 6-minute walk distance (6MWD); obesity and COPD with worse functional class; and diabetes and COPD with increased risk of death [3]. Likewise, a grey zone of patients with Pulmonary Capillary Wedge Pressure (PCWP) 16 to $18 \mathrm{~mm} \mathrm{Hg}$ who were diagnosed and treated for PAH has been analyzed: they were older, heavyweight, and more likely to have comorbidities associated with left ventricular diastolic dysfunction at diagnosis than those with PCWP $\leq 15 \mathrm{~mm} \mathrm{Hg}$. Fiveyear survival rates were similarly low for all PCWP subgroups [4]. Another report examined the influence of age on phenotypes of incident pulmonary arterial hypertension and showed the changes in demographics and epidemiology over the past decade in a national setting, suggesting that there may be two subtypes of patients: the youngest subtype with more severe hemodynamic impairment but better survival, and the oldest subtype which has more comorbidities [5].

The impact of coexistent left heart disease in COPD should be taken into account in clinical practice, as cardiovascular disease increases morbidity and mortality significantly. In one recent study, transthoracic echocardiography performed prospectively in more than 300 patients with COPD 3 months after discharge from the hospital after an acute exacerbation demonstrated significant cardiac alterations in $64 \%$ of patients: $27 \%$ left- and $48 \%$ right-heart disorders with a frequency of $\mathrm{PH}$ around $19 \%$. Interestingly, left ventricle systolic dysfunction, left ventricle diastolic impairment, and left atrial dilatation were present in $29 \%, 12 \%$, and $13 \%$ of the COPD patients respectively. Noticeably, echocardiographic abnormalities were unrelated to COPD severity [6]. The prevalence and the prognostic implications of the simultaneity of left ventricular dysfunction in COPD patients and airway obstruction in Congestive Heart Failure (CHF) patients were shown in another recent prospective study which included stable $\geq 60$-yr-old patients with echocardiographic confirmed CHF $(n=201)$ and stable $\geq 60$-yr-old patients with clinically and spirometryconfirmed COPD $(n=218)$. Previously unrecognized left ventricular dysfunction occurred in $17 \%$ of COPD with a significant influence on the survival rate [7].

The coexistence of emphysema and pulmonary fibrosis in the same patient results in a clinical syndrome, known as combined pulmonary fibrosis and emphysema (CPFE), that is characterized by dyspnea, upper-lobe emphysema, lower-lobe fibrosis, and abnormalities of gas exchange almost only in male older smokers. This syndrome is frequently complicated by pulmonary hypertension with increased mortality [8].

A retrospective multicentre study in 40 patients reported severe PH in CPFE patients and 60\% survival at one year. Surprisingly, lung volumes and flows were relatively preserved while exercise capacity resulted severely compromised; moreover, haemodynamics were the most significant prognostic indexes [9].

$\mathrm{PH}$ is a well-recognized complication of interstitial lung disease, including idiopathic pulmonary fibrosis (IPF) and its prevalence has been estimated from $32 \%$ to $85 \%$. There is a highly significant difference between survival of IPF patients with and without PH [10]. Hypoxia, destruction of pulmonary vascular bed or fibroproliferative phenomena might be important mechanisms in individual patients. However, the correlation of $\mathrm{PH}$ with forced vital capacity (FVC) is weak and patients with severe $\mathrm{PH}$ and still preserved lung volumes could also be seen [11]. Severe pulmonary hypertension can occur in idiopathic NSIP, even in the absence of advanced radiographic changes, especially when $\mathrm{DL}_{\mathrm{CO}}$ is severely reduced [12].

Out-of-proportion $\mathrm{PH}$ is defined as the unjustified increase in $\mathrm{PH}$ that is observed in patients affected by different types of parenchymal lung disease [COPD, IPF, Obstructive Sleep Apnea, (OSA), Obesity Hypoventilation Syndrome (OHS), etc.]. The term 'out-of-proportion $\mathrm{PH}^{\prime}$ was introduced recently into the field of PH. Until few years ago the term 'pulmonary heart' was used to indicate the development of $\mathrm{PH}$-correlated parenchymal diseases and presence of chronic hypoxia leading to chronic respiratory failure and, as a consequence, right heart failure. But in the last few years better understanding of the mechanisms underlying structural remodeling of the pulmonary vascular bed raised the doubt that all can be explained by the presence of pulmonary heart. Indeed, some patients can develop extremely high pulmonary artery pressure that cannot be explained by hypoxia and remodeling of the pulmonary vascular bed alone. Due to an increasing use of right heart catheterization for selection of candidates for lung transplantation, a number of patients affected by parenchymal lung diseases (often accompanied by minor lung impairment on lung function tests and/or 
CT) with a not easily explainable degree of $\mathrm{PH}$ have come to the attention of doctors. In these patients the development of moderate to severe $\mathrm{PH}$, that cannot be explained by the degree of parenchymal lung disease and hypoxia has been defined out-of-proportion $\mathrm{PH}$, and an arbitrary value of PAPm> $35 \mathrm{~mm} \mathrm{Hg}$ has been established to identify these patients. However, the use of the term out of proportion $\mathrm{PH}$ is questionable. Indeed, a direct relationship between ventilator impairment and pulmonary haemodinamics has not been documented in COPD yet. Instead severe respiratory $\mathrm{PH}$ phenotype seems a more appropriate term, according to recent data based on ASPIRE Registry [13]. In this study 59 patients with COPD and severe pulmonary hypertension had significantly lower carbon monoxide diffusion, less severe airflow obstruction but not significantly different emphysema scores on computed tomography compared to 42 patients with mild-moderate pulmonary hypertension. 1- and 3-year survival for severe pulmonary hypertension, at $70 \%$ and $33 \%$, respectively, was inferior to $83 \%$ and $55 \%$, respectively, for mild-moderate pulmonary hypertension. Moreover, mixed venous oxygen saturation, carbon monoxide diffusion, World Health Organization functional class and age, but not severity of airflow obstruction, were independent predictors of outcome. Remarkably, improvement in functional class and/ or fall in pulmonary vascular resistance $>20 \%$ following targeted treatment identified patients with improved survival.

The diagnosis would be pulmonary hypertension rather than pulmonary arterial hypertension; in fact increased pressures are the result of another disease rather than of diseased arteries. Nonetheless, patients can have both idiopathic pulmonary arterial hypertension and interstitial lung disease contemporaneously. An expert on pulmonary hypertension is required to evaluate such patients and make the correct diagnosis. If through the examination with right heart catheterization the specialist evaluates that the pulmonary hypertension is out of proportion with respect to the lung disease, the patient can be treated. In brief, mild lung disease usually does not advance to severe pulmonary hypertension.

\section{Pulmonary hypertension and COPD}

COPD, defined as a persistent and progressive airflow obstruction, is complicated by numerous comorbidities or associated conditions, as also by frequent episodes of acute exacerbation. Generally, alterations are mainly located in the small airways. Pulmonary hypertension due to chronic respiratory disease and/or hypoxemia represents Group 3 of the Dana Point (2009) clinical classification of $\mathrm{PH}$ [14]. This group includes forms of $\mathrm{PH}$ due to COPD, pulmonary fibrosis and/or combined pulmonary diseases, in other words chronic infections in which signs of emphysema are visible in the upper lobes and fibrosis in the lower. $\mathrm{PH}$ due to respiratory diseases is considered a hemodynamic alteration associated to, and a consequence of, the primary disease, as distinct from the idiopathic form that represents the true disease in which the pulmonary vessels are involved from the very outset.

In terms of definition it is important to underline the meaning of 'out of proportion'. Cut-off values $>35$ and/ or $>40 \mathrm{mmHg}$ of PAPm are employed in the literature to define out-of-proportion respiratory $\mathrm{PH}$. This definition was used in the recent guidelines of the European Respiratory Society/European Society of Cardiology [15]. Numerous studies have documented the clinical impact of $\mathrm{PH}$ on mortality in COPD patients. Although there is not unanimous agreement about the definition of 'out-of-proportion $\mathrm{PH}$ ', as a general rule it is considered to be any value of $\mathrm{PH}$ in COPD patients with mildto-moderate ventilatory impairment (forced expiratory volume in $1 \mathrm{sec}\left[\mathrm{FEV}_{1}\right]>50 \%$ predicted) or a mPAP > $40 \mathrm{~mm} \mathrm{Hg}$ in the presence of severe ventilatory deficit but without comorbidities. It should also be noted that in COPD patients levels of mPAP between 21 and $24 \mathrm{~mm} \mathrm{Hg}$ are considered a pre- $\mathrm{PH}$ condition and further studies are required to establish the clinical impact of this range. By 'chronic pulmonary heart' definition it is meant hypertrophy and dilation of the right ventricle secondary to $\mathrm{PH}$ due to chronic pulmonary disease. However, this term is inappropriate in clinical practice both because the observation of right ventricle anomalies varies according to the method used and because peripheral edema, a clinical surrogate of chronic pulmonary heart, could appear in COPD patients with normal or low central venous pressure. Exercise-induced $\mathrm{PH}$ could be used in clinical research but at the moment there is no consensus about the definition. In conclusion, at present $\mathrm{PH}$ is defined as resting pulmonary pressure $>$ $25 \mathrm{~mm} \mathrm{Hg}$, pulmonary capillary wedge pressure $<15$ $\mathrm{mm} \mathrm{Hg}$, and/or a reduced cardiac output as measured hemodynamically in COPD patients.

\section{Pathogenesis of PH secondary to COPD}

$\mathrm{PH}$ associated to COPD is of a pre-capillary type with low or normal cardiac output and is in particular determined by pulmonary vascular remodeling that provokes an increase in the pulmonary vascular resistance (PVR). Characteristically, it has been shown that cigarette smoking causes vascular remodeling even in early phases of the disease, promoting endothelial dysfunction and airways inflammation. Chronic alveolar hypoxia is responsible for the remodeling of the pulmonary arterioles in particular in people living at high altitude; thus, in COPD patients pulmonary vascular remodeling seems to be the leading 
cause of PH and not hypoxia, since vascular impairments have been described even in the absence of hypoxemia and long term oxygen therapy does not modify the course of PH in COPD. Nonetheless, local inflammation at the level of the small pulmonary arteries associated to hypoxemia can contribute to pulmonary vascular remodeling.

\section{Hemodynamic characteristics}

Generally PH in COPD is pre-capillary at rest, but PH with elevated capillary pressure is frequently observed in COPD patients with associated emphysema and/or in the presence of comorbidities such as left heart dysfunction. The peculiar nature of the right ventricle, that shows capacity to adapt to the rising afterload and therefore a slow progression towards a functional impairment has to be expected. This feature would explain the wellpreserved contractility of the right ventricle at rest and in phase of clinical stability as well as the slow development of PH. In fact in COPD patients and other patients with chronic lung disease, $\mathrm{PH}$ is usually of a mildmoderate level: this constitutes an important distinction from the other forms of $\mathrm{PH}$, those of Groups 1 or 4 of the Dana Point classification. Even if PH is mild or moderate at rest, then PAP increases markedly during sleep, physical exercise and, in particular, during exacerbations. Approximately $10-20 \%$ of COPD patients at the advanced stage present severe $\mathrm{PH}$ with $\mathrm{PAP}>35 \mathrm{~mm} \mathrm{Hg}$, and this is observed in 3 clinical conditions: a) in patients with severe hypoxemia and hypercapnia associated to severe airflow limitation in whom an increase in resting mPAP can be seen in clinically stable conditions; b) in patients with associated comorbidities such as chronic venous thromboembolism, severe left heart disease or an associated restrictive pulmonary disease; and c) in patients with modest functional limitation associated to severe hypoxemia and hypocapnia. This last condition is defined as out-of-proportion PH. The hemodynamic alterations observed in this form of IP are similar to those observed in the idiopathic form. Recent data from the National Emphysema Treatment Trial indicate that the finding of severe $\mathrm{PH}$ at rest is a rare event in emphysema in the absence of comorbidities.

\section{Clinical impact}

The pathogenetic mechanisms underlying dyspnea in COPD patients consist largely in hyperinflation, increased ventilatory demand, muscle weakness and, in more severe patients, hypoxemia and hypercapnia. Nevertheless, the impact of $\mathrm{PH}$ on symptoms during exercise is not well established yet, nor it is established if modest increases in mPAP contribute to dyspnea in the course of exercise. In fact, a recent study compared patients with COPD and severe $\mathrm{PH}$ with mild-moderate hyperinflation to patients with COPD and mild $\mathrm{PH}$ associated to more severe airways limitation who manifested a greater exercise intolerance. More recently it has still been shown that COPD patients with mPAP $>40 \mathrm{~mm} \mathrm{Hg}$ present a reduced circulatory reserve at end of exercise in contrast to ventilatory reserve exhaustion observed in COPD patients with less severe $\mathrm{PH}$. These findings suggest that lung hemodynamics plays an important role in exercise-related dyspnea in COPD patients with severe $\mathrm{PH}$ (mPAP> $40 \mathrm{~mm} \mathrm{Hg}$ ) and not in patients with mild-moderate $\mathrm{PH}$.

\section{Exercise capacity}

Retrospective studies have documented that elevated levels of mPAP are associated to a reduced distance walked in meters on the 6MWT [16] and to a lower maximal power during incremental cardiopulmonary exercise test compared to patients with airways function limitation but mild PH [17]. During the obstructive event the transmural pulmonary arterial pressure is modified in inverse proportion to the level of hypoxia, even if the addition of $\mathrm{O}_{2}$ does not modify this condition.

\section{$\mathrm{PH}$ associated to OSA}

Pulmonary hypertension has been demonstrated in approximately $17-42 \%$ of patients with obstructive sleep apnea syndrome (OSAS) $[18,19]$. Determining factors in the onset of pulmonary hypertension seem to be $\mathrm{PaO}_{2}$, $\mathrm{PaCO}_{2}$ and $\mathrm{FEV}_{1}$. Studies on animal cell lines have documented that intermittent hypoxia acts as a far more potent stimulus than continuous hypoxia on the activation of multiple transcription factors; among these we find hypoxiainducible factor-1 (HIF-1), with its second messengers, erythropoietin and vascular endothelial growth factor

\section{Table 1 Prevalence of $\mathrm{PH}$ in OSA patients}

\begin{tabular}{lcc}
\hline Study & Sample size & PH prevalence (\%) \\
\hline Schroeder et al. [22] & 22 & 59 \\
Tilkian et al. [23] & 12 & 67 \\
Fletcher et al. [24] & 24 & 79 \\
Podszus et al. [25] & 65 & 20 \\
Weitzenblum [26] & 46 & 20 \\
Krieger et al. [27] & 114 & 19 \\
Sajkov et al. [28] & 27 & 41 \\
Laks et al. [18] & 100 & 42 \\
Chaouat et al. [29] & 220 & 17 \\
Sanner et al. [30] & 92 & 20 \\
Bady et al. [31] & 44 & 27 \\
Sajkov et al. [32] & 32 & 34 \\
Alchanatis et al. [33] & 29 & 21 \\
Arias [34] & 23 & 43 \\
Dumitrascu [35] & 45 & 20 \\
\hline
\end{tabular}

Modified from [36]. 
(VEGF), that together with endothelin-1 (ET-1) are responsible for the structural and pressure modifications [20].

The association of pulmonary hypertension due to hypoventilation and exercise capacity, and the haemodynamic and functional changes, under non-invasive ventilation, has been recently characterized with the presence of severe $\mathrm{PH}$, increase in pro-BNP, and low exercise capacity at baseline, which improved significantly after three months of non invasive ventilation [21]. The PH prevalence estimated in OSA patients is shown in Table 1.

\section{Pulmonary hypertension in obesity hypoventilation syndrome}

Obesity places a significant load on the respiratory system, affecting lung volumes, respiratory muscle function, work of breathing, and ventilatory control. Despite this, most morbidly obese individuals maintain eucapnia. However, a subgroup of morbidly obese individuals will develop chronic daytime hypercapnia, described as the Obesity Hypoventilation Syndrome (OHS).

OHS is defined as a disease characterized by:

1. Obesity: $\mathrm{BMI} \geq 30 \mathrm{~kg} / \mathrm{m}^{2}$

2. Chronic alveolar hypoventilation

3. Daytime (awake) hypercapnia $\left(\mathrm{PaCO}_{2} \geq 45 \mathrm{~mm} \mathrm{Hg}\right)$

4. (OSA) sleep respiratory disorders (AHI $\geq 5$ with or without hypoventilation during sleep) present in $90 \%$ of cases; hypoventilation during sleep $(\mathrm{AHI}<5)$ present in $10 \%$ of cases.

The prevalence of estimated PH in OHS is very high, and is between 59 and $88 \%$ [37]. Patients with OHS have a lower quality of life with increased health-care expenses and are at a higher risk for the development of pulmonary hypertension and early mortality compared to eucapnic patients with sleep-disordered breathing. Despite the significant morbidity and mortality associated with this syndrome, it is often unrecognized and treatment is frequently delayed.

\section{Conclusions}

Pulmonary hypertension associated to respiratory diseases is a multifactorial disorder which may complicate, and seriously modify, the prognosis of the principal disease. The management and the treatment of this important complication must be evaluated by a team of specialists, including cardiologists, pulmonologists and rheumatologists.

This small review showed the most common disorders associated to pulmonary hypertension, in which the physician has the pivotal role to investigate as soon as possible the presence of this complication, in order to early identify the phenotype associated to the worst outcome.

\section{Abbreviations}

COPD: Chronic obstructive pulmonary disease; IPF: Idiopathic pulmonary fibrosis; OHS: Obesity hypoventilation syndrome; OSA: Obstructive sleep apnea; PH: Pulmonary hypertension; PAH: Pulmonary arterial hypertension.

\section{Competing interests}

The authors declare that they have no competing interests.

\section{Authors' contributions}

LC conceived and supervised the study, PC designed the study and wrote the manuscript, MS conceived the study, designed the study and wrote the manuscript. All authors read and approved the final manuscript.

\section{Acknowledgements}

The Authors wish to thank Dr. Anna AgneseStanziola for her collaboration and valuable comments in the editing of this manuscript.

\section{Author details}

${ }^{1}$ Respiratory Diseases, University of Perugia, Perugia, Italy. ${ }^{2}$ Institute of Pulmonary Diseases, University of Medicine, Bari, Italy. ${ }^{3}$ Respiratory Diseases, Monaldi Hospital, University Federico II, Naples, Italy.

Received: 8 November 2013 Accepted: 15 November 2013 Published: 26 November 2013

\section{References}

1. Task Force for Diagnosis and Treatment of Pulmonary Hypertension of European Society of Cardiology (ESC); European Respiratory Society (ERS); International Society of Heart and Lung Transplantation (ISHLT), Galiè N, Hoeper MM, Humbert M, Torbicki A, Vachiery JL, Barbera JA, Beghetti M, Corris P, Gaine S, Gibbs JS, Gomez-Sanchez MA, Jondeau G, Klepetko W, Opitz C, Peacock A, Rubin L, Zellweger M, Simonneau G: Guidelines for the diagnosis and treatment of pulmonary hypertension. Eur Respir J 2009, 34:1219-1263.

2. Galiè N, Palazzini M, Manes A: Pulmonary hypertension and pulmonary arterial hypertension: a clarification is needed. Eur Respir J 2010, 36:986-990.

3. Poms AD, Turner M, Farber HW, Meltzer LA, McGoon MD: Comorbid conditions and outcomes in patients with pulmonary arterial hypertension: a REVEAL registry analysis. Chest 2013, 144:169-176. doi:10.1378/chest.11-3241.

4. Frost AE, Farber HW, Barst RJ, Miller DP, Elliott CG, McGoon MD: Demographics and outcomes of patients diagnosed with pulmonary hypertension with pulmonary capillary wedge pressures 16 to $18 \mathrm{~mm}$ Hg: insights from the REVEAL Registry. Chest 2013, 143(1):185-195.

5. Ling Y, Johnson MK, Kiely DG, Condliffe R, Elliot CA, Gibbs JS, Howard LS, Pepke-Zaba J, Sheares KK, Corris PA, Fisher AJ, Lordan JL, Gaine S, Coghlan JG, Wort SJ, Gatzoulis MA, Peacock: Changing demographics, epidemiology, and survival of incident pulmonary arterial hypertension: results from the pulmonary hypertension registry of the United Kingdom and Ireland. Am J Respir Crit Care Med 2012, 186(8):790-796.

6. Freixa X, Portillo K, Paré C, Garcia-Aymerich J, Gomez FP, Benet M, Roca J, Farrero E, Ferrer J, Fernandez-Palomeque C, Antó JM, Barberà JA: PAC-COPD study investigators: echocardiographic abnormalities in patients with COPD at their first hospital admission. Eur Respir J 2013, 41(4):784-791.

7. Macchia A, Rodriguez Moncalvo JJ, Kleinert M, Comignani PD, Gimeno G, Arakaki D, Laffaye N, Fuselli JJ, Massolin HP, Gambarte J, Romero M, Tognoni G: Unrecognised ventricular dysfunction in COPD. Eur Respir J 2012, 39(1):51-58.

8. Jankowich MD, Rounds SI: Combined pulmonary fibrosis and emphysema syndrome: a review. Chest 2012, 141(1):222-231.

9. Cottin V, Le Pavec J, Prévot G, Mal H, Humbert M, Simonneau G, Cordier JF, GERM"O"P: Pulmonary hypertension in patients with combined pulmonary fibrosis and emphysema syndrome. Eur Respir J 2010, 35(1):105-111.

10. Castria D, Refini RM, Bargagli E, Mezzasalma F, Pierli C, Rottoli P: Pulmonary hypertension in idiopathic pulmonary fibrosis: prevalence and clinical progress. Int J Immunopathol Pharmacol 2012, 25(3):681-689.

11. Smith JS, Gorbett D, Mueller J, Perez R, Daniels CJ: Pulmonary hypertension and idiopathic pulmonary fibrosis: a dastardly duo. Am J Med Sci 2013 346:221-225. 
12. Hallowell RW, Reed RM, Fraig M, Horton MR, Girgis RE: Severe pulmonary hypertension in idiopathic nonspecific interstitial pneumonia. Pulm Circ 2012, 2(1):101-106.

13. Hurdman J, Condliffe R, Elliot CA, Swift A, Rajaram S, Davies C, Hill C, Hamilton N, Armstrong IJ, Billings C, Pollard L, Wild JM, Lawrie A, Lawson R, Sabroe I, Kiely DG: Pulmonary hypertension in COPD: results from the ASPIRE registry. Eur Respir J 2013, 41:1292-1301.

14. Proceedings of the 4th world symposium on pulmonary hypertension, February 2008, Dana Point, California, USA. J Am Coll Cardiol 2009, 30(1):S1-117.

15. Chaouat A, Naeije R, Weitzenblum E: Pulmonary hypertension in COPD. Eur Respir J 2008, 32(5):1371-1385.

16. Modrykamien AM, Gudavalli R, McCarthy K, Parambil J: Echocardiography, 6-minute walk distance, and distance-saturation product as predictors of pulmonary arterial hypertension in idiopathic pulmonary fibrosis. Respir Care 2010, 55(5):584-588.

17. Laveneziana P, Garcia G, Joureau B, Nicolas-Jilwan F, Brahimi T, Laviolette L, Sitbon O, Simonneau G, Humbert M, Similowski T: Dynamic respiratory mechanics and exertional dyspnoea in pulmonary arterial hypertension. Eur Respir J 2013, 41(3):578-587.

18. Laks L, Lehrhaft B, Grunstein RR, Sullivan CE: Pulmonary hypertension in obstructive sleep apnoea. Eur Respir J 1995, 8(4):537-541.

19. Kessler R, Chaouat A, Weitzenblum E, Oswald M, Ehrhart M, Apprill M, Krieger J: Pulmonary hypertension in the obstructive sleep apnoea syndrome: prevalence, causes and therapeutic consequences. Eur Respir $J$ 1996, 9:787-794

20. Belaidi E, Joyeux-Faure M, Ribuot C, Launois SH, Levy P, Godin-Ribuot D: Major role for hypoxia inducible factor-1 and the endothelin system in promoting myocardial infarction and hypertension in an animal model of obstructive sleep apnea. J Am Coll Cardiol 2009, 53:1309-1317.

21. Held M, Walthelm J, Baron S, Roth C, Jany B: Functional impact of pulmonary hypertension due to hypoventilation and changes under NIPPV. Eur Respir J 2013 [Epub ahead of print].

22. Schroeder JS, Motta J, Guilleminault C: Haemodynamic studies in sleep apnoea. In Sleep apnea syndromes. Edited by Guilleminault C, Dement WC. New York: Alan R. Liss; 1978:177-196.

23. Tilkian AG, Guilleminault C, Schroeder JS, Lehrman KL, Simmons FB, Dement WC: Hemodynamics in sleep-induced apnea. Studies during wakefulness and sleep. Ann Intern Med 1976, 85:714-719.

24. Fletcher EC, Schaaf JW, Miller J, Fletcher JG: Long-term cardiopulmonary sequelae in patients with sleep apnea and chronic lung disease. Am Rev Respir Dis 1987, 135:525-533.

25. Podszus T, Bauer W, Mayer J, Penzel T, Peter JH, von Wichert P: Sleep apnea and pulmonary hypertension. Klin Wochenschr 1986, 64:131-134.

26. Weitzenblum E, Krieger J, Apprill M, Vallée E, Ehrhart M, Ratomaharo J, Oswald M, Kurtz D: Daytime pulmonary hypertension in patients with obstructive sleep apnea syndrome. Am Rev Respir Dis 1988, 138:345-349.

27. Krieger J, Sforza E, Apprill M, Lampert E, Weitzenblum E, Ratomaharo J: Pulmonary hypertension, hypoxemia, and hypercapnia in obstructive sleep apnea patients. Chest 1989, 96:729-737

28. Sajkov D, Cowie RJ, Thornton AT, Espinoza HA, McEvoy RD: Pulmonary hypertension and hypoxemia in obstructive sleep apnea syndrome. Am J Respir Crit Care Med 1994, 149:416-422.

29. Chaouat A, Weitzenblum E, Krieger J, Oswald M, Kessler R: Pulmonary hemodynamics in the obstructive sleep apnea syndrome: results in 220 consecutive patients. Chest 1996, 109:380-386.

30. Sanner BM, Doberauer C, Konermann M, Sturm A, Zidek W: Pulmonary hypertension in patients with obstructive sleep apnea syndrome. Arch Intern Med 1997, 157:2483-2487.

31. Bady E, Achkar A, Pascal S, Orvoen-Frija E, Laaban JP: Pulmonary arterial hypertension in patients with sleep apnoea syndrome. Thorax 2000 55:934-939.

32. Sajkov D, Wang T, Saunders NA, Bune AJ, Neill AM, Douglas Mcevoy R: Daytime pulmonary hemodynamics in patients with obstructive sleep apnea without lung disease. Am J Respir Crit Care Med 1999, 159:1518-1526.

33. Alchanatis M, Tourkohoriti G, Kakouros S, Kosmas E, Podaras S, Jordanoglou JB: Daytime pulmonary hypertension in patients with obstructive sleep apnea: the effect of continuous positive airway pressure on pulmonary hemodynamics. Respiration 2001, 68:566-572.
34. Arias MA, Garcia-Rio F, Alonso-Fernandez A, Martínez I, Villamor J: Pulmonary hypertension in obstructive sleep apnoea: effects of continuous positive airway pressure: a randomized, controlled cross-over study. Eur Heart $J$ 2006, 27:1106-1113.

35. Dumitrascu R, Tiede H, Eckermann J, Mayer K, Reichenberger F, Ghofrani HA, Seeger W, Heitmann J, Schulz R: Sleep apnea in precapillary pulmonary hypertension. Sleep Med 2013, 14(3):247-251.

36. Sajkov D, McEvoy RD: Obstructive sleep apnea and pulmonary hypertension. Prog Cardiovasc Dis 2009, 51(5):363-370.

37. Mokhlesi B, Tulaimat A: Recent advances in obesity hypoventilation syndrome. Chest 2007, 132(4):1322-1336.

doi:10.1186/2049-6958-8-72

Cite this article as: Casali et al:: Clinical variability of respiratory pulmonary hypertension: implications for diagnosis and management. Multidisciplinary Respiratory Medicine 2013 8:72.

\section{Submit your next manuscript to BioMed Central and take full advantage of:}

- Convenient online submission

- Thorough peer review

- No space constraints or color figure charges

- Immediate publication on acceptance

- Inclusion in PubMed, CAS, Scopus and Google Scholar

- Research which is freely available for redistribution 